\title{
The Innovative Process in the Interruption of Wind Power in Portugal
}

\author{
António Brito , and Luís Neves \\ Energy Purchase Department, EDP Serviço Universal SA, Portuguese Last Resort Supplier, Coimbra, Portugal
}

\begin{abstract}
The production of energy under a special regime of renewable origin has had a sustainable evolution in Portugal. Since the 1990s, the percentage of renewables has been growing steadily, with special emphasis being given to wind, photovoltaic, mini-hydro, biogas and high-efficiency cogeneration [1]. More recently there has been a strong push in promoting small scale production and self-consumption [2]. There are several periods of time when the country's electricity load is $100 \%$ supplied by renewable energy. There are also periods when surplus renewable energy is exported to Spain. However, there are some periods when production exceeds consumption and it is then necessary to reduce wind power production. In Portugal there is an innovative process underway to carry out this reduction, which was systematized by the General Department of Energy and Geology in Order No. 8810/2015, of August 10. Thus, in the case of wind power plants that receive power reduction orders, the remuneration equivalent to that which is lost is paid by the other producers, through the Last Resort Supplier. Those power plants that have not been interrupted pay a percentage of their power produce to the Last Resort Supplier, to compensate those that have been interrupted. The total of the payments made to the producers whose power plants were interrupted must equal the receipts from those plants that continued to produce energy. This new concept is exemplified in this paper by the wind power cut that occurred on March 12 and 13, 2017 in Portugal. An explanation of what occurred on that day is presented, to understand why this cut was made, having been reached the limits of energy exports to Spain. To implement this new interruptible compensation model it was necessary to develop a mathematical algorithm and include it in the computer application named GPCE - Producers' Management and Energy Purchase, that belongs to the Last Resort Supplier. When the interruption occurred in March 2017, the computer system worked correctly. The sum of the payments made equaled the sum of the receipts. It should be noted that there was a high degree of discipline shown by the producers.
\end{abstract}

\section{Introduction - Evolution of wind energy in Portugal}

Production under a special regime in Portugal began with the publication of Decree-Law $n^{\circ} 189 / 88$, of May 27. With the publication of Decree-Law no 339-C / 2001, of December 29, there was an improvement in the remuneration for wind power generation. This fact has led to a significant increase in the number of installed wind power plants in Portugal. Thus, it gave an initial boost to the new technology that was emerging. There have been progressive reductions in the cost of new power plants through the scale effect.

As wind technology has been disseminated, energy acquisition prices have been reduced, namely through Decree Law 33-A / 2005, of February 16, and 225/2007, of May 31. The graph below shows the significant increase in the production of wind energy in GWh, whose yearly production is represented in green.

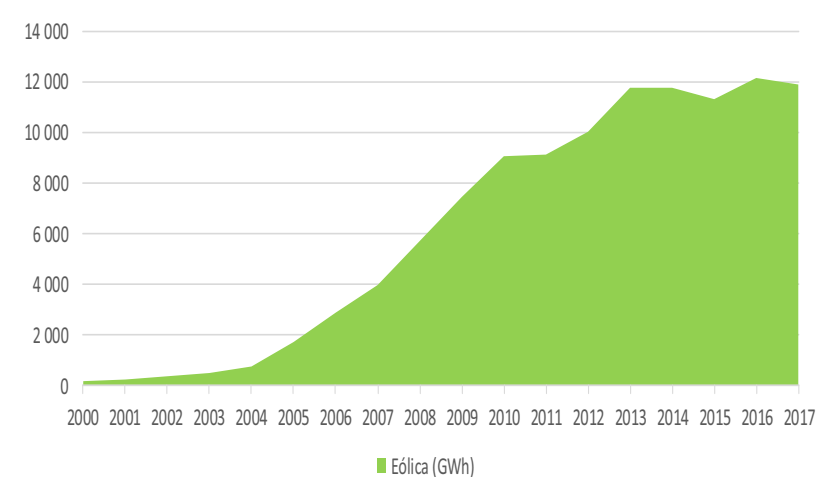

Graph 1. Evolution of wind power energy generation in Continental Portugal, in GWh, during the period from 2000 till 2017.

At the end of 2017 the total power installed in wind power plants was $5578 \mathrm{MVA}$. 
The next graph represents the evolution of installed power since the year 2000, in apparent power (MVA). At present, new wind power plants with a total power of 232.4 MVA are under construction.

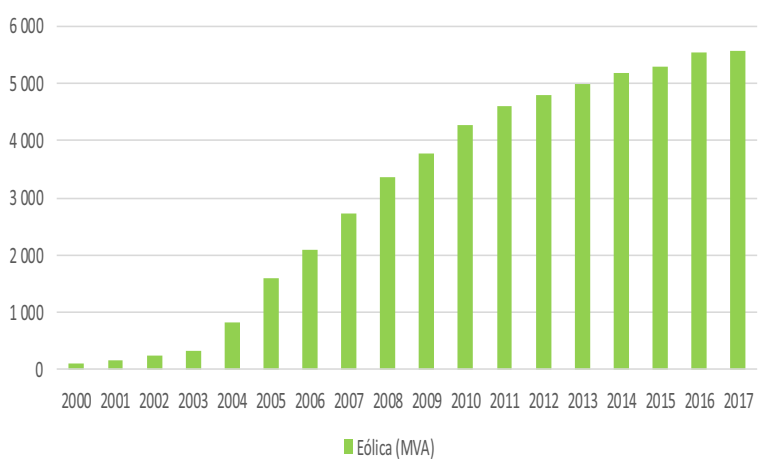

Graph 2. Evolution of wind installed power in Continental Portugal, in MVA, during the period from 2000 till 2017.

Later, in 2010, through Decree-Law no. 51/2010, of May 20, over-capacity of wind power plants was allowed. This was done through the reduction of global remuneration. The placement of equipment to support tensioning was encouraged. Thus, all wind turbines of a wind power plant that were connected to the transmission or to the distribution network were required to have installed equipment installed to support voltage tanks and provide reactive power during troughs.

The producers' representatives carried out various studies demonstrating that the probability that all wind turbines were producing energy at maximum power was very low. Thus, not overcoming the value of the bonding power, the Decree-Law 94/2014, of June 24, allowed them to produce this additional energy at a low price of $60 € /$ MWh.

Considering the great expansion of wind power, it became necessary to limit the reactive energy emitted to be able to control the voltage levels in the transmission and distribution networks.

More recently, under certain circumstances, there has been a need to interrupt the supply of electricity. The problem has arisen because it was needed to reduce the power or to disconnect certain wind power plants, while others are producing. This would cause complaints that led to the question: Why was my wind power plant cut off? To be solves this problem, the new concept of interrupting arose, in which no one is impaired.

\section{What happened on march 12 and 13, 2017}

From 3:00 p.m. to 6:30 p.m. on March 12 (Sunday), the Transportation Network Dispatcher had to reduce wind production in Portugal for the first time. The magnitude of the reduction was about $90 \mathrm{MW}$ (less than $3 \%$ of the wind production that occurred at that time) [3]. At 9:25 p.m. it was again necessary to reduce the wind generation that was being injected into the grid. This time the magnitude of the reduction was around $80 \mathrm{MW}$. As the mentioned reduction was not enough, at $22 \mathrm{~h} 02$, an additional $80 \mathrm{MW}$ was reduced, leading to a total reduction of $160 \mathrm{MW}$ of wind inject power. At 4:24 am on March 13, the reduction instructions were canceled [3].

The reductions in power mentioned above preserved the balance between production and consumption, since it was not possible to export energy to Spain. In the chart following it can be regarded that the instructions issued by the Transmission System Operator were accomplished by the wind farms and their dispatch centers [3].

Thus, at the beginning of the first limitation period, the power concerning only wind production was 4510 MW and the consumption was $4828 \mathrm{MW}$. Considering the procedures mentioned above, it was possible to reduce the power by $90 \mathrm{MW}$. At the end of the first limitation period the power being produced had dropped, so that production and consumption could be balanced. At the start of the second limitation period, power increased again. It was then necessary to reduce power by $80 \mathrm{MW}$. Unfortunately, this reduction was not enough and it was necessary to reduce again by another $80 \mathrm{MW}$.

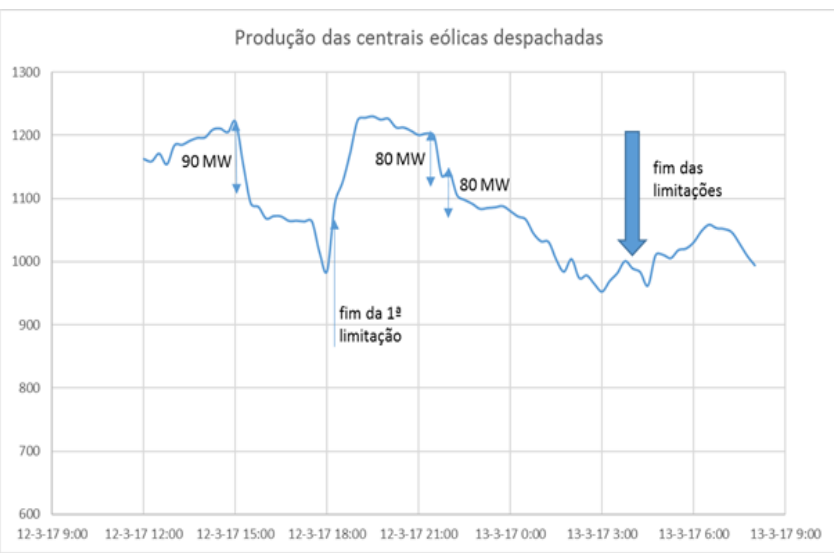

Graph 3. [3] - Power produced by wind farms, in MW, on March 12 (9 am, 12 am., 6 pm., 9 pm.) and on March 13 (0 am, 3 am, 6 am, 9 am)

Immediately before the decision to reduce power the transportation network was in an extreme situation, always needing to safeguard the security of supply and the balance between production and consumption.

The power cuts were decided as a last resort to maintain the balance of the system, considering that [3]:

- The consumption was reduced as it is typical of a Sunday with moderate temperature.

- The market program had put all thermal power plants out of service.

- The import programs resulting from the wholesale market had already been canceled.

- Hydro generation had already been reduced to the minimum.

- Hydro pumping had already been mobilized and was partially depleted.

The reduction instructions were limited, in both duration and quantity, to the strict minimum needed to keep the system balanced. The fact that the special regime production had exceeded consumption over a long period of time can be seen in the graph below. The black 
line represents consumption. As it can be seen, the production of renewable energy exceeded the country's consumption needs and part of that energy was exported to Spain.

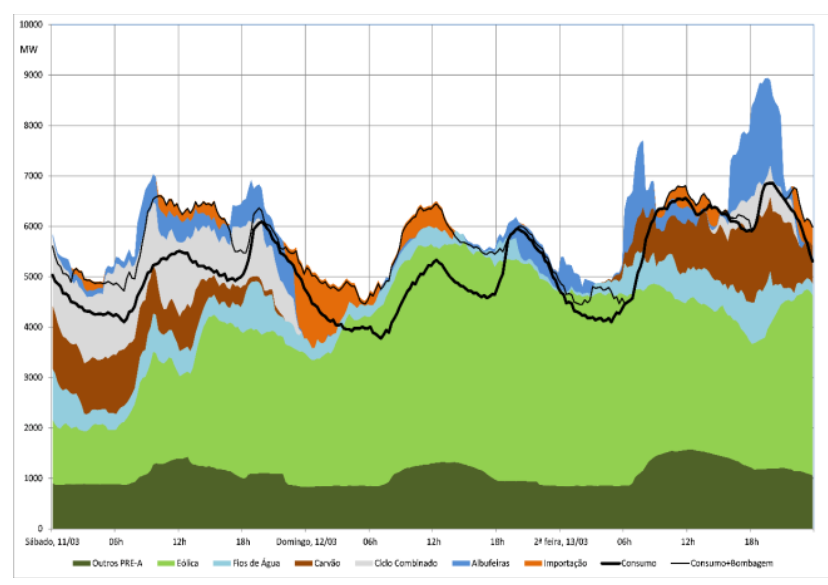

Graph 4. [3] - Diagram of power production, in MW, from March 11 to March 13, 2017.

\section{The concept of interruption}

Electricity production centers that use renewable energy sources and high-efficiency cogeneration benefit from priority access to networks, according to European Union directives. The Portuguese legislation also provides that Operators of the Public Utility Electricity Network must take appropriate operational measures to prevent or minimize the establishment of limitations in the transportation and distribution of electricity from these power generation centers. The legislation also contemplates the possibility of imposing limitations on the transportation and distribution of electricity from power plants under a special regime, due to reasons related to the reliability and security of supply of the networks. The interruption of production under a special regime may occur in which the Portuguese electricity system is exploited, as it is preview in the Regulations of the Transmission and Distribution Networks. These regulations provide for the possibility of congestion due to the unavailability of equipment or the inability to dispose of the injection of additional energy and overproduction from wind power plants. Therefore, it has been necessary to lay down arrangements for interrupting production under a special regime that profits from a system of support for remuneration - known as feed-in tariffs.

Thus, the agents involved in this cut off process are the following:
a) Last Resort Supplier
b) Global System Technical Manager
c) Transport System Operator
d) Distribution System Operator

e) Producers under a special regime who benefit from a support to remuneration (feed-in tariffs), excluding small distributed production, normally connected to the low voltage network.
In exceptional situations of exploitation of the Portuguese electrical system, particularly when congestions occur or when safety in the productionconsumption balance are in danger and the continuity of the electric power supply is in question, power reduction orders may be issued. In these cases, the production of special production power plants (linked to the transmission or distribution network) must be monitored so that these installations do not exceed a given power value.

The issuing of power reduction orders is the exclusive task for the Global System Technical Manager. The Distribution System Operator may request that the manager issue a power reduction order, when the operating situations in the distribution network require it. Power reduction orders are mandatory for producers under a special regime, specifying the beginning and end of the interruption period and the maximum power value that can be produced by the power plant. The power reduction order is issued and sent as far in advance as possible, with at least a minimum of 5 minutes before the beginning of the reduction period. The power plants that are subject to power reduction orders that are issued by the Global System Technical Manager or, when applicable, by the Distribution System Operator, have a maximum period of 15 minutes to adjust their production to the value requested in that order.

Producers who have been subject to a power reduction order have the right to receive remuneration equivalent to the production that would have result if no reduction order had been issued. This remuneration is paid by those producers who have not received power reduction orders.

All producers not subject to power reduction orders are obliged to pay a contribution to the producers whose production have been interrupted.

Thus, the Global System Technical Manager, or the Distribution System Operator must inform the Last Resort Supplier, whenever they issue a production reduction order, identifying for each interruption:

a) Producers who have been targeted for the reduction of power, as well as the start and end date and the time of the reduction;

b) Producers that were producing when the reduction order was issued and the electric energy they produced during the reduction order.

Thus, the Global System Technical Manager and the Distribution System Operator agreed the format of the computer file that is to be sent to the Last Resort Supllier containing the information necessary to perform the calculations of the remuneration to be paid and to receive from the producers. A protocol was signed between the Global System Technical Operator and the Last Resort Supplier relating to the operationalization of the information exchange, so that calculations of the remuneration to be paid and to be received from producers can be made in the software application GPCE - Producers' Management and Energy Purchase.

In the following figure the format of part of the mentioned file, which is emitted in the format csv comma separated values, can be seen. 
The index key of the file's registers into the databases is achieved through a delivery point code. This codification complies with European Union standards and is unique for each European Union installation.

Inicio;2017;03;12;15;00;

Fim;2017;03;12;15;30;

PRE Limitacao;PT0001000000000168NC;84832;

PRE_Limitacao;PT0001906000100036VH;10629;

Racio;2017;03;12;15;15;1.000000;

Racio;2017;03;12;15;30;1.000000;

Dados;PT0001000000000168NC;2017;03;12;15;15;0

.000;0.000;0.000; $\mathrm{N}$

Dados;PT0001000000000168NC;2017;03;12;15;30;0 .000;0.000;0.000; $\mathrm{N}$;

Dados;PT0001906000100036VH;2017;03;12;15;15;0 $.000 ; 0.000 ; 0.000 ; \mathrm{N}$;

Fig. 1. Example of a file format used in interruption calculations

The above file must be sent to the Last Resort Supplier within the first 10 working days of the following month $(\mathrm{m}+1)$ for the reduction of production. This information should be used for the billing of the energy purchased from producers in month $\mathrm{m}+2$ or $\mathrm{m}+3$.

The Last Resort Supplier will have to proceed as follows: for educated producers, where there are limitations imposed, the estimated production not carried out by each insulation is multiplied by the average energy sales price of the installation verified in month $\mathrm{m}$, for each identified producer. The amount obtained shall be added to the billing of each producer in month $\mathrm{m}+2$ or $\mathrm{m}+3$.

The Last Resort Supplier will have to proceed as follows:

a) for instructed producers, where there were limitations imposed, the estimated production not carried out by each installation is multiplied by the average energy sales price for that power plant verified in month $\mathrm{m}$. The amount obtained shall be added to the billing of each producer in month $\mathrm{m}+2$ or $\mathrm{m}+3$;

b) The aggregate value of the amounts to be paid to the identified producers shall be allocated to producers who have not suffered a power reduction and that produced energy during the period in which limitation was imposed. The amount obtained is deducted from the billing of each producer in month $\mathrm{m}+2$ or $\mathrm{m}+3$.

\section{Computer development}

To carry out the mentioned calculations it was necessary to make a new module in the GPCE - Producers' Management and Energy Purchase computer application. At present, the number of producers under a special regime in Portugal is 1025 , with about $75 \%$ of them adhering to electronic self-billing. Electronic billing has simplified the process of reconciliation with producers, where some receive money and others pay. The computer system must ensure that the total paid is equal to the total received.
The following figure shows the screen shot of the interruption module, which is divided into four entries: a) file loading, b) retribution calculations, c) control reports and $d$ ) circular sending. The process is completely automated, as it would be difficult to perform such calculations in a short period of time.

\section{INTERRUPTION \\ ENTRANCE SCREEN}

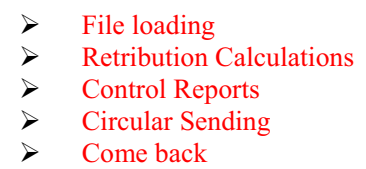

Fig. 2. Input interrupt module screen of the GPCE Application

c) File Loading - Files from the Global System Technical Manager or from the Distribution System Operator are sent to the Last Resort Supplier in the format shown in Figure 1. These files are inputed into the computer system using the screen shown in figure 3 below. Using this screen, the various versions that have been sent are controlled, as well as the corrections that have been made.

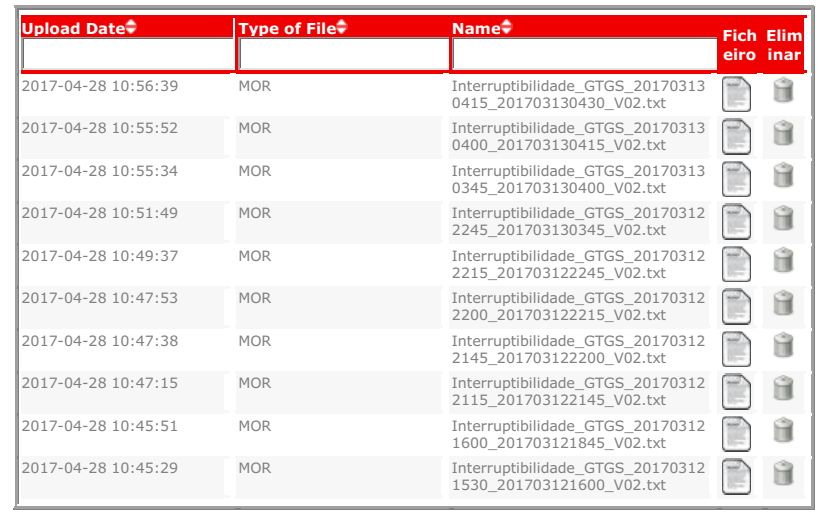

Fig. 3. Example of a file loading screen.

d) Retribution calculations - Calculations are performed and controlled through the screen shown in figure 4 (on the next page). The estimated undone production, in $\mathrm{kWh}$, corresponds to the estimate of production that would have rsulted if a producer had not received reduction orders. This estimate, for each power plant, corresponds to the average value of power that is reduced every 15 minutes, and is verified in the period immediately preceding the first period in which the power reduction order was issued and the 15 minutes power comfirmed in the period immediately after that in which the limitation ends. If there are very long periods of limitation, this way of estimating production then does not reflect reality. The Global System Technical Manager will then calculate the energy estimation using the best information available, in order to approximate this estimate to reality.

e) Reporting - It is necessary to obtain several reports to control the calculations made. These calculations and the amounts obtained are communicated to the General Department of Energy and Geology for 
validation. After explaining the values obtained and getting authorization, the calculations are closed (see Figure 5 below).

\section{INTERRUPTION RETRIBUTION CALCULATIONS}

$>$ Exhibit

$>$ Create / Recalculate

$>$ Associate File

$>$ Cut Out

$>$ Historic

$>$ Come back

Fig. 4. Retribution calculations screen.

\section{INTERRUPTION REPORTING}

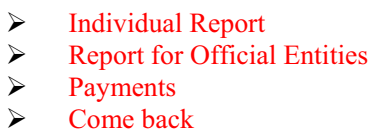

Fig. 5. Reporting and controlling of calculations screen.

d) Circular sending - After the calculations have been aproved, the Last Resort Supplier sends circulars to the producers involved, indicating the amounts to be added to or to be deducted from the billing of the month $\mathrm{m}+2$ or $\mathrm{m}+3$.

Fortunately, $75 \%$ of producers have adhered to electronic self-billing, which significantly simplifies the billing process. For those who still send paper invoices it was necessary to establish a control of the amounts paid and received. Circulars are sent automatically using email (see Figure 6 below).

\section{INTERRUPTION}

CIRCULAR SENDING

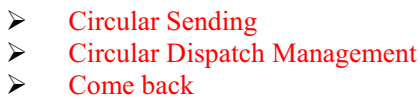

Fig. 6. Circular sending screen.

\section{Conclusions}

The interruption process described in this paper is already being used and it is an innovation, that allows power that is injected into the network to be reduced, when necessary. The producers affected do not suffer a loss of revenue. The amounts paid by the remaining producers is relatively small, that does not cause any disturbance in their remuneration. The interruption described is very satisfactory: The Global System Technical Manager achieves his goal of reducing power. The producers whose power plants suffered a reducing of power receive the compensation and the other producers participate in that compensation. There had been no complaints till now. It can be concluded that the implementation of this new process has been a success. We strongly recommend the use of this new concept that has been described in this paper.

\section{Acknowledgment}

The authors would like to express their gratitude to the colleague Pedro Lourenço who, as business analyst, developed the software system and tested it. The system worked as expected when the interruption occurred on March 12 and 13, 2017.

\section{References}

1. A. Brito, L. Neves (2013), The feed-in tariffs structure of renewable and cogeneration energy in Portugal, $13^{\circ}$ Congresso Luso Espanhol de Engenharia Eletrotécnica, Valência, 2013

2. P. Lourenço., C. Almeida (2018), Production under feed-in tariffs in Portugal, International Conference on Renewable Energies and Power Quality (ICREPQ'17), that was held in the University of Malaga on 4 till 6 April, 2018.

3. Incident Report. Wind Power Cut, March 12 and 13 (2017). REN - Redes Energéticas Nacionais, Portugal. 